\begin{tabular}{|c|l|}
\hline Title & Hydrogenolysis of sugar beet fiber by supported metal catalyst \\
\hline Author(s) & Guha, Samar K.; Kobay ashi, Hirokazu; Hara, Kenji; Kikuchi, Hiroto; A ritsuka, Tsutomu; Fukuoka, A tsushi \\
\hline Citation & $\begin{array}{l}\text { Catalysis Communications, 12(11), 980-983 } \\
\text { https://doi.org/10.1016/.catcom.2011.02.017 }\end{array}$ \\
\hline Issue Date & 2011-06-10 \\
\hline Doc URL & http://hdl.handle.net/2115/46769 \\
\hline Type & article(author version) \\
\hline File Information & CC12-11_980-983.pdf \\
\hline
\end{tabular}

Instructions for use 


\title{
Hydrogenolysis of sugar beet fiber by supported metal catalyst
}

\author{
Samar K. Guha ${ }^{\mathrm{a}}$, Hirokazu Kobayashi ${ }^{\mathrm{a}}$, Kenji Hara ${ }^{\mathrm{a}}$, Hiroto Kikuchi ${ }^{\mathrm{b}}$, \\ Tsutomu Aritsuka , Atsushi Fukuoka*a \\ ${ }^{a}$ Catalysis Research Center, Hokkaido University, Kita 21 Nishi 10, Kita-ku, Sapporo 001-0021, Japan \\ ${ }^{b}$ Research Center, Nippon Beet Sugar Manufacturing, Co., Ltd., Minami 9 Nishi 13, Inada-cho, Obihiro \\ 080-0831, Japan
}

* Corresponding author. Fax: +81-11-706-9139.
E-mail address: fukuoka@cat.hokudai.ac.jp (A. Fukuoka)

\begin{abstract}
Sugar beet fiber is an agricultural by-product in the sugar manufacturing and an available biomass source with a rich hemicellulose component. So far, there has been no report on the catalytic conversion of the beet fiber for the synthesis of chemicals. In this work, the hydrogenolysis of the beet fiber was studied by using supported metal catalysts under pressurized hydrogen conditions. Activated carbon supported Ru was found to show the highest catalytic activity to give arabitol as a major product in the hydrogenolysis of hemicellulose part of this material. The reuse ability of the catalyst was also investigated.
\end{abstract}

Key Words: Beet fiber, Hemicellulose, Hydrogenolysis, Supported metal catalyst, Arabitol, Arabinose.

\section{Introduction}

Utilization of non-food biomass is important for the production of renewable chemicals to decrease net carbon dioxide accumulation to the atmosphere. Lignocellulose is a typical non-food 
biomass, which contains 50-80\% fermentable carbohydrates such as cellulose and hemicellulose by dry weight [1-3]. Although extensive efforts have been given for the conversion of cellulose to fuels and chemicals [4-6], a limited number of works have been done for the conversion of hemicellulose. Hemicellulose is the second most abundant polysaccharides in nature (20-35\% of lignocellulosic biomass) consisting of hexoses and pentoses, where the main components of pentoses are xylose and arabinose [7]. Recently, conversion of hemicellulose has received much attention because of its potential industrial use in many fields as well as a raw material for the production of furfural and ethanol [8-13]. However, enzymes and homogeneous catalysts have been utilized in the reactions, which have serious drawbacks such as insufficient activity, difficult separation of products and enzymes or catalysts, corrosive properties, and expensive solvents. Very recently, the hydrolysis of hemicellulose was reported using solid acids as heterogeneous catalysts [14].

Sugar beet fiber (hereafter beet fiber) is an agricultural by-product obtained after extraction of sucrose from sugar beet in the sugar manufacturing, and the worldwide annual production of sugar beet is over 400 million ton [15]. It is an easily available source for lignocellulosic polysaccharides including hemicellulose derivatives. The amount of hemicellulose in beet fiber ranges from 22 to $36 \%$ [16-20], which depends on the source and the procedure of determination. It is believed that arabinan, the polysaccharide of $\mathrm{C}_{5}$ arabinose, is the major compound (ca. 80\%) of that hemicellulose part [21]. Other constituents of hemicellulose of beet fiber are galactose (15\%), xylose (5\%), and mannose (5\%) [15]. Therefore, beet fiber is a suitable resource for the production of arabinose and the corresponding alcohol (arabitol), and the latter compound has been selected as a top 12 value-added products from biomass by US Department of Energy [22]. It is noteworthy that very few works have been done on the conversion of beet fiber by microbial fermentation [23, 24] and by the hydrolysis of beet fiber using enzymes or homogeneous acids [25-27], causing the problems described above. To our knowledge arabitol has not been directly obtained from beet fiber in a single process. Arabitol is a potential precursor to biologically active substrates. Therefore, the production of arabitol from beet fiber still remains a challenge in this field. 
Previously, we reported the catalytic hydrogenolysis of cellulose to sorbitol by supported metal catalysts [28, 29]. In this work, we have studied the hydrogenolysis reaction of hemicellulose in beet fiber as a real biomass source by using various supported metal catalysts, and arabitol was obtained selectively in good yields (Scheme 1). The effect of the reaction parameters and reuse experiments were also investigated.

\section{Scheme 1}

\section{Experimental}

\subsection{Preparative procedure of catalysts}

For the preparation of carbon supported catalysts, a solution of $\mathrm{RuCl}_{3} \cdot 3 \mathrm{H}_{2} \mathrm{O}(0.106 \mathrm{~g})$ or $\mathrm{Ru}(\mathrm{NO})\left(\mathrm{NO}_{3}\right)_{3}(0.128 \mathrm{~g})$ in $\mathrm{H}_{2} \mathrm{O}(10 \mathrm{~mL})$ was added to a mixture of activated carbon (Wako, denoted as $\mathrm{AC}(\mathrm{W}), 2.00 \mathrm{~g})$ and $\mathrm{H}_{2} \mathrm{O}(40 \mathrm{~mL})$. The mixture was stirred for $16 \mathrm{~h}$ at room temperature, evaporated to dryness, and dried under vacuum for overnight. The resulting sample was reduced ex situ with $\mathrm{H}_{2}\left(30 \mathrm{~mL} \mathrm{~min}^{-1}\right)$ at $673 \mathrm{~K}$ for $2 \mathrm{~h}$ to give $\mathrm{Ru} / \mathrm{AC}(\mathrm{W})(\mathrm{Ru} 2 \mathrm{wt} \%)$. After reduction, He gas was passed through the resulting catalyst for a few minutes to remove $\mathrm{H}_{2}$ and then it was collected under air. Similarly, Ru/carbon catalysts were prepared using activated carbon obtained from Norit (denoted as AC(N)) and carbon blacks (BP2000 and XC72 from Cabot and Ketjen Black EC-600JD from Lion). The surface area and the particle size of the carbon supports were determined and found to be different from each other. The values are: particle sizes $\mathrm{AC}(\mathrm{W}) 47 \mu \mathrm{m}, \mathrm{AC}(\mathrm{N}) 36 \mu \mathrm{m}$, BP2000 $22 \mu \mathrm{m}$, XC72 $10 \mu \mathrm{m}$, and Ketjen Black $98 \mu \mathrm{m}$; surface area AC(W) $1380 \mathrm{~m}^{2} / \mathrm{g}, \mathrm{AC}(\mathrm{N})$ $1010 \mathrm{~m}^{2} / \mathrm{g}$, BP2000 $1440 \mathrm{~m}^{2} / \mathrm{g}$, XC72 $209 \mathrm{~m}^{2} / \mathrm{g}$, and Ketjen Black $1400 \mathrm{~m}^{2} / \mathrm{g}$. In the preparation of Pt catalysts (Pt 2 wt\%), $\mathrm{H}_{2} \mathrm{PtCl}_{6}$ was used as the precursor. A similar method was used for the preparation of $\gamma-\mathrm{Al}_{2} \mathrm{O}_{3}$-supported catalysts. In this case, the impregnated alumina samples were calcined with $\mathrm{O}_{2}\left(30 \mathrm{~mL} \mathrm{~min}^{-1}\right)$ at $673 \mathrm{~K}$ for $2 \mathrm{~h}$ before reduction with $\mathrm{H}_{2}\left(30 \mathrm{~mL} \mathrm{~min}{ }^{-1}\right.$ at $673 \mathrm{~K}$ for $2 \mathrm{~h}$ ). $\mathrm{N}_{2}$ adsorption measurements were performed at $77 \mathrm{~K}$ using a Belsorp-mini II. 


\subsection{Typical procedure for hydrogenolysis of beet fiber}

Beet fiber was supplied from Nippon Beet Sugar Manufacturing, Co., Ltd. Dried beet fiber powder (320 mg), 2 wt\% Ru/AC(W) (200 mg), and distilled water (40 mL) were charged in a $100 \mathrm{~mL}$ stainless steel (SUS316) autoclave (OM Lab-Tech MMJ-100, $100 \mathrm{~mL}$ ), and then pressurized with $\mathrm{H}_{2}$ gas of $5 \mathrm{MPa}$. The reactor was heated to 403 or $428 \mathrm{~K}$ and maintained at the temperature for 24 $\mathrm{h}$ with stirring at $600 \mathrm{rpm}$. Then the reactor was cooled to room temperature, and the liquid part was separated by centrifugation. The solution containing the water-soluble products was analyzed by using a Shimadzu LC10-ATVP high performance liquid chromatography (HPLC, refractive index detector). The columns used in this work were a Phenomenex Rezex RPM-Monosaccharide Pb++ (ø7.8x300 mm, mobile phase: water $0.6 \mathrm{~mL} \mathrm{~min}^{-1}$, $353 \mathrm{~K}$ ) and a Shodex Sugar SH-1011 (ø8x300 $\mathrm{mm}$, mobile phase: water $0.5 \mathrm{~mL} \mathrm{~min}^{-1}$, $323 \mathrm{~K}$ ). The yields of arabitol and arabinose were based on the weight of hemicellulose as the molar calculation was difficult. It should be noted that the determination of hydrogen consumption is impossible, because the amount of hydrogen consumption will be in the error level of material balance $(\sim 1 \%)$ as the final pressure in the reactor was the same as the initial pressure (5 MPa). It should also be noted that $100 \mathrm{mg}$ of Ru-catalyst and $195 \mathrm{mg}$ of Pt-catalyst contains the same 0.02 mg-atom of metal. The conversion of beet fiber was determined from the weight difference of the solid residue after the reaction.

\subsection{Typical procedure for recovery of the catalyst and the recycle reactions}

After finishing the reaction with the fresh catalyst, the reaction mixture was centrifuged and the residue was separated from the liquid part under air. The residue, which contained the recovered catalyst and the unreacted beet fiber, was used for the next recycle reaction without any treatment. In the recycle reactions, the amount of reagents and the reaction conditions were exactly the same as described in Section 2.2, and the reaction temperature was $428 \mathrm{~K}$. In this case, the conversion of beet fiber had not been calculated as the residue was not dried to determine the weight of the unused 
beet fiber. After filtering the water soluble part from the reaction mixture, the wet residue was used for the next recycle reaction.

\section{Results and Discussion}

First of all, the composition of hemicellulose, cellulose, and lignin in the supplied beet fiber was determined by the Van Soest's method [30, 31]. It was found that the beet fiber contained 23\% hemicellulose, 24\% cellulose, and 3\% lignin. It is reported that other parts include pectin (ca. 20\%) [18], and these values are almost the same as the previously reported data $[16,17]$. The remaining constituents of beet fiber are reported to be protein (10\%), ash (3\%), and fat (1\%) [16-20].

The screening of catalysts was investigated for the hydrogenolysis of beet fiber, and Table 1 summarizes the results. Initially, $\mathrm{Ru} / \gamma-\mathrm{Al}_{2} \mathrm{O}_{3}, \mathrm{Pt} / \gamma-\mathrm{Al}_{2} \mathrm{O}_{3}, \mathrm{Pt} / \mathrm{AC}(\mathrm{W})$, and $\mathrm{Ru} / \mathrm{AC}(\mathrm{W})$ were used for the hydrogenolysis reaction at $403 \mathrm{~K}$ for $24 \mathrm{~h}$ under a $\mathrm{H}_{2}$ pressure of $5 \mathrm{MPa}$ (entries 1-5). Among the catalysts, $\mathrm{Ru} / \mathrm{AC}(\mathrm{W})$ gave the highest yield of arabitol as a major product (33\%) with arabinose of $19 \%$ (total 52\%) (entry 5). It should be mentioned that some oligomers and other by products such as ethylene glycol, propylene glycol, and glycerol were also obtained together with arabinose and arabitol (entries 1-5). The catalysis of $\mathrm{Ru} / \mathrm{AC}(\mathrm{W})$ is obvious when the distribution of the products is compared with a non-catalyzed reaction, in which arabinose was produced in 56\% yield without the formation of arabitol (entry 1). Arabinose is probably obtained from the arabinan polysaccharide, which is known as a major constituent of the hemicellulose part of beet fiber. The arabinan polysaccharide is easily hydrolyzed to arabinose by in-situ formed $\mathrm{H}_{3} \mathrm{O}^{+}$in hot compressed water. The $\mathrm{pK}_{\mathrm{w}}$ value of $\mathrm{H}_{2} \mathrm{O}$ at $403 \mathrm{~K}$ has been reported to be 11.9 [32]. However, due to the absence of a catalyst, the second hydrogenation step did not proceed in this reaction. Thus, the major role of $\mathrm{Ru} / \mathrm{AC}(\mathrm{W})$ catalyst is the reduction of arabinose formed from the hydrolysis of hemicellulose of beet fiber.

In the cases of $\mathrm{Ru} / \gamma-\mathrm{Al}_{2} \mathrm{O}_{3}$ and $\mathrm{Pt} / \gamma-\mathrm{Al}_{2} \mathrm{O}_{3}$-catalyzed reactions, the yields of arabitol were low, showing the low hydrogenation rates of arabinose (entries 2, 3). The low activity is probably due to 
the contamination of some constituents of beet fiber, which reduce the catalytic activity of the alumina-supported catalysts for this hydrogenation reaction. It was confirmed by doing the hydrogenation of arabinose (pure reagent) at $403 \mathrm{~K}$ for $1 \mathrm{~h}$ by $\mathrm{Ru} / \gamma-\mathrm{Al}_{2} \mathrm{O}_{3}$ and $\mathrm{Pt} / \gamma-\mathrm{Al}_{2} \mathrm{O}_{3}$ catalysts, and arabitol was obtained in 32\% and 55\% yield, respectively.

These results motivated us to study the detail of the catalytic reactions using $\mathrm{Ru} / \mathrm{AC}(\mathrm{W})$. By increasing the amount of $\mathrm{Ru} / \mathrm{AC}(\mathrm{W})$ catalyst, the yield of arabitol was increased (entries 5, 6), which suggests that the higher amount of catalyst facilitates the reduction of arabinose to arabitol. The optimization of the reaction conditions was performed by changing the parameters of the reaction, e.g., temperature, reaction time, amount of catalysts, substrate/catalyst ratio, and $\mathrm{H}_{2}$ pressure, and it was found that the reaction conditions shown in entry 12 of Table 1 gave the highest yield of arabitol. The optimum $\mathrm{H}_{2}$ pressure for the hydrogenation reaction was $5 \mathrm{MPa}$, and no major change was observed even at $10 \mathrm{MPa}$. On the other hand, under $0.1 \mathrm{MPa}$ of $\mathrm{H}_{2}$, only the hydrolysis of beet fiber occurred to form arabinose, but arabitol was not obtained. The optimized substrate/catalyst weight ratio was 1.6 (entry 12). Considering the high price of Ru metal, the catalyst weight was reduced to $20 \mathrm{mg}$ (the substrate/catalyst weight ratio 16), but arabitol was obtained only in 6\% yield together with arabinose in 9\% yield (entry 18). Under the optimized reaction conditions, $\mathrm{C}_{6}$ sugars and sugar alcohols were also obtained in almost all cases. The formation of $\mathrm{C}_{6}$ sugars and sugar alcohols is attributed to the reaction of cellulose part of beet fiber. As the present reaction conditions are too mild for cellulose hydrolysis, the yields of the $\mathrm{C}_{6}$ sugars and sugar alcohols are low (1-6\%).

Several carbon supports for Ru were also investigated, and the results are shown in Table 1 (entries 12, 14-17). It was found that $\mathrm{AC}(\mathrm{W}), \mathrm{AC}(\mathrm{N})$, and carbon blacks BP2000 and Ketjen Black showed almost the same catalytic activity, whereas a carbon black XC72 gave poor activity. This is probably due to low surface area of XC72 compared with other carbon supports. Among the tested catalysts, $\mathrm{Ru} / \mathrm{AC}(\mathrm{W})$ (prepared from $\mathrm{RuCl}_{3}$ precursor) showed the highest yield of arabitol in the hydrogenolysis of beet fiber (83\%, entry 12$)$. In this reaction, the remaining by-products were 
ethylene glycol (2\%), propylene glycol (8\%), and glycerol (5\%). Another Ru/AC(W) prepared from $\mathrm{Ru}(\mathrm{NO})\left(\mathrm{NO}_{3}\right)_{3}$ precursor showed the same yield of the products (entry 13). The support material itself was also used as a catalyst under the same reaction conditions (entry 9), but only a small amount of arabinose was obtained (13\%). In comparison to a non-catalyzed reaction (Entry 8), this low yield indicates that $\mathrm{AC}(\mathrm{W})$ does not promote the depolymerization of hemicellulose to arabinose, and that $\mathrm{Ru}$ metal promotes the hydrogenation of arabinose to arabitol. The yield of arabinose in the reactions without catalysts rather reduced from $56 \%$ to $17 \%$ by increasing the reaction temperature from $403 \mathrm{~K}$ to $428 \mathrm{~K}$ (entries 1,8 ) due to the thermal decomposition of arabinose, which is contrastive tendency to the increase of arabitol by $\mathrm{Ru} / \mathrm{AC}(\mathrm{W})$ catalyst (entries 6 , 7). These results indicate the good chemical stability of arabitol and the potency of the one-step synthesis of arabitol.

\section{Table 1}

Reuse experiments were performed by using $\mathrm{Ru} / \mathrm{AC}(\mathrm{W})$ catalyst. Unfortunately, it did not show recycle ability in the hydrogenolysis of beet fiber. The catalytic activity was started to decrease from the first recycle reaction. By using a fresh catalyst, 83\% arabitol was obtained, whereas only $48 \%$ arabitol was obtained in the first recycle reaction. The yield of arabitol was decreased gradually, and finally arabitol was not formed in the fourth recycle test. In order to overcome that problem, the used catalyst (after the first reaction) was subjected to regenerate by reduction with $\mathrm{H}_{2}$, but it did not show any positive effect towards the recycle reactions. There are several reasons for the catalyst deactivation in the recycle reactions. For example, i) deactivation occurred by the presence of chloride ion of $\mathrm{RuCl}_{3}$ precursor, ii) leaching of metal during the reaction, iii) contamination of some components of beet fiber with the catalyst, and iv) pore blocking by substrates or products. In order to check those assumptions, another Ru/AC(W) catalyst prepared from a $\mathrm{Ru}(\mathrm{NO})\left(\mathrm{NO}_{3}\right)_{3}$ precursor was also used for the recycle reactions. It showed the 
same tendency of $\mathrm{Ru} / \mathrm{AC}(\mathrm{W})$ prepared from $\mathrm{RuCl}_{3}$ precursor, which rules out the possibility of the catalyst deactivation by the chlorides ions. The ICP-AES of the water soluble part proved that no leaching of Ru occurred during the reaction. The EDX and CHNS analyses of beet fiber showed that beet fiber contained S $(<0.3 \%)$ as well as some metals. The contamination of those materials with the catalyst was also confirmed from the EDX analysis of the used catalyst. Probably, S and those metals adsorbed on Ru metal to reduce the active sites of the catalyst. We therefore assumed that some constituents of beet fiber covered the catalyst to inhibit the active sites of the catalyst for the hydrogenation reaction.

In order to check the possibility of pore-blocking, the $\mathrm{N}_{2}$ adsorption experiments were performed for the fresh catalyst and the used one. It was found that the Brunauer-Emmett-Teller (BET) surface area of fresh $\mathrm{Ru} / \mathrm{AC}(\mathrm{W})$ was $1390 \mathrm{~m}^{2} \mathrm{~g}^{-1}$ and the pore volume was $1.54 \mathrm{~cm}^{3} \mathrm{~g}^{-1}$, whereas those of the used $\mathrm{Ru} / \mathrm{AC}(\mathrm{W})$ was $350 \mathrm{~m}^{2} \mathrm{~g}^{-1}$ and $0.45 \mathrm{~cm}^{3} \mathrm{~g}^{-1}$, respectively. The decrease of the parameters indicates that the pore is blocked by substrates or products. As a result, the available $\mathrm{Ru}$ species for the reaction was decreased which caused the deactivation of the catalyst in the recycle reactions of beet fiber.

For further consideration, the reuse experiments were performed by using arabinose as a substrate instead of beet fiber. Interestingly, the catalyst was found to remain active with an almost unchanged selectivity even after the third reuse (Table 2, entries 19-22). In these cases, some gaseous products might be formed together with the cracking products. Finally, the catalyst after the third reuse was used for the hydrogenolysis of beet fiber (entry 23). The desired product, arabitol was obtained in $83 \%$ yield, which is the same as obtained with a fresh catalyst (83\%, entry 12 of Table 1) in the hydrogenolysis of beet fiber. This result clearly shows that Ru/AC(W) catalyst is stable enough for the reuse experiments for arabinose, and that the catalyst is not deactivated by arabinose, arabitol, and their derivatives. The problem in the recycle reactions of beet fiber is therefore arising from beet fiber. In order to find out the exact reason for the deactivation of the catalyst in the recycle reaction of beet fiber, further reactions are now on investigation. 
Table 2

\section{Conclusion}

We have developed a new procedure for the catalytic hydrogenolysis of beet fiber. Arabitol was obtained selectively in very good yields by $\mathrm{Ru} / \mathrm{AC}(\mathrm{W})$ catalyst from the hydrogenolysis of hemicellulose constituent of beet fiber. By this study, beet fiber will have a potential place in the list of chemical feedstocks.

\section{Acknowledgements}

This work was supported by a Grant-in-Aid for Scientific Research (KAKENHI, 20226016) from the Japan Society for the Promotion of Science (JSPS). The authors thank Ms. M. Watanabe and Ms. Y. Ito for their experimental assistance.

\section{References}

[1] S. Prasad, A. Singh, H. C. Joshi, Resour. Conserv. Recycl. 50 (2007) 1-39.

[2] D. L. Klass, Biomass for Renewable Energy, Fuels, and Chemicals, Academic Press, San Diego, 1998.

[3] L. R. Lynd, C. E. Wyman, T. U. Gerngross, Biotechnol. Prog.C. E. Wyman, 15 (1999) 777793.

[4] Y. Sun, J. Cheng, Bioresour. Technol. 83 (2002) 1-11.

[5] G. W. Huber, S. Iborra, A. Corma, Chem. Rev. 106 (2006) 4044-4098.

[6] S. K. Guha, H. Kobayashi, A. Fukuoka, in: M. Crocker (Ed.), Thermochemical Conversion of Biomass to Liquid Fuels and Chemicals, Royal Society of Chemistry, Cambridge, 2010, pp. 344-364.

[7] C. E. Wyman, Bioresour. Technol. 50 (1994) 3-16. 
[8] L. Viikari, M. Tenkanen, J. Buchert, M. Ratto, M. Bailey, M. Siikaaho, M. Linko, in: J. N. Saddler (Ed.), Bioconversion of forest and agricultural plant residues, CAB, Oxford, 1993, pp. 131-182.

[9] K. K. Y. Wong, L. U. L. Tan, J. N. Saddler, Microbiol. Rev. 52 (1988) 305-317.

[10] J. G. Zeikus, C. Lee, Y. E. Lee, and B. C. Saha, in: G. F. Leatham, M. E. Himmel (Eds.), Enzymes in biomass conversion, American Chemical Society, Washington D.C., 1991, pp. $36-51$.

[11] B. C. Saha, J. Ind. Microbiol. Biotechnol. 30 (2003) 279-291.

[12] S. Hisaku, J. Abe, JP Patent 3834152, 2006.

[13] J. B. Binder, R. T. Raines, J. Am. Chem. Soc. 131 (2009) 1979-1985.

[14] P. L. Dhepe, R. Sahu, Green Chem. 12 (2010) 2153-2156.

[15] M. D. Sutton, J. B. D. Peterson, J. Sugar Beet Res. 38 (2001) 19-34.

[16] T. Aritsuka, K. Tanaka, S. Kiriyama, J. Jpn. Soc. Nutr. Food Sci. 42 (1989) 295-304.

[17] N. Nishimura, H. Nishikawa, S. Kiriyama, Nutr. Metab. (1993) 1260-1269.

[18] H. Kikuchi, T. Aritsuka, New Food Ind. 41 (1999) 21-26.

[19] S. Karlander, I. Armyr, S. Efendic, Diabetes Res. Clin. Pract. 11 (1991) 65-72.

[20] H. Vural, I. Javidipour, O. O. Ozbas, Meat Sci. 67 (2004) 65-72.

[21] H. Kikuchi and A. Fukuoka, JP Patent 313590, 2008.

[22] http://www1.eere.energy.gov/biomass/pdfs/35523.pdf, (2004)

[23] H. Hara, S. Haga, T. Kasai, S. Kiriyama, J. Nutr. 128 (1998) 688-693.

[24] F. Guillon, A. Auffret, J. A. Robertson, J. -F. Thibault, J. -L. Barry, Carbohydr. Polym. 37 (1998) 185-197.

[25] H. Tanaka, G. Yoshikawa, WO Patent 0157230, 2001.

[26] H. Kikuchi, R. Sakamoto, M. Tamura, T. Nagura, T. Aritsuka, H. Sakurai, K. Sayama, JP Patent 2002-45194, 2002.

[27] T. Funako, T. Ono, JP Patent 2009-273398, 2009. 
[28] A. Fukuoka, P. L. Dhepe, Angew. Chem. Int. Ed. 45 (2006) 5161-5163.

[29] H. Kobayashi, Y. Ito, T. Komanoya, Y. Hosaka, P. L. Dhepe, K. Kasai, K. Hara, A. Fukuoka, Green Chem. 13 (2011) 326-333.

[30] P. J. Van Soest, J. Assoc. Off. Anal. Chem. 46 (1963) 829-835.

[31] P. J. Van Soest, R. H. Wine, J. Assoc. Off. Anal. Chem. 50 (1967) 50-55.

[32] W. L. Marshall, E.U. Franck, J. Phys. Chem. Ref. Data 10 (1981) 295-304. 
Captions:

Scheme 1. Hydrogenolysis of sugar beet fiber. 
Research highlights.

$>$ Catalytic hydrogenolysis of sugar beet fiber to arabitol in a one pot reaction. > $\mathrm{Ru} /$ carbon catalyst for hydrolysis and hydrogenation of arabinan in hemicellulose. > Hydrolysis by in-situ formed proton in hot compressed water. > Supported metal catalysts for reduction of arabinose under pressurized hydrogen. 
Table 1

Screening of catalysts for the hydrogenolysis of beet fiber ${ }^{\mathrm{a}}$.

\begin{tabular}{|c|c|c|c|c|c|c|}
\hline \multirow[t]{2}{*}{ Entry } & \multirow[t]{2}{*}{ Catalyst } & \multirow{2}{*}{$\begin{array}{l}\text { Amount of } \\
\text { catalyst [mg] }\end{array}$} & \multirow{2}{*}{$\begin{array}{l}\text { Temp. } \\
{[\mathrm{K}]}\end{array}$} & \multirow{2}{*}{$\begin{array}{l}\text { Conv. }^{b} \\
{[\%]}\end{array}$} & \multicolumn{2}{|c|}{ Yield $^{\mathrm{c}, \mathrm{d}, \mathrm{e}}[\%]$} \\
\hline & & & & & Arabinose & Arabitol \\
\hline 1 & None & - & 403 & 67 & 56 & N.d. \\
\hline 2 & $\mathrm{Ru} / \gamma-\mathrm{Al}_{2} \mathrm{O}_{3}$ & 100 & 403 & 68 & 54 & 2 \\
\hline 3 & $\mathrm{Pt} / \gamma-\mathrm{Al}_{2} \mathrm{O}_{3}$ & 195 & 403 & 68 & 41 & 14 \\
\hline 4 & $\mathrm{Pt} / \mathrm{AC}(\mathrm{W})$ & 195 & 403 & 60 & 35 & 9 \\
\hline 5 & $\mathrm{Ru} / \mathrm{AC}(\mathrm{W})$ & 100 & 403 & 65 & 19 & 33 \\
\hline 6 & $\mathrm{Ru} / \mathrm{AC}(\mathrm{W})$ & 150 & 403 & 64 & 7 & 51 \\
\hline 7 & $\mathrm{Ru} / \mathrm{AC}(\mathrm{W})$ & 150 & 428 & 70 & 2 & 77 \\
\hline 8 & None & - & 428 & 69 & 17 & N.d. \\
\hline 9 & $\mathrm{AC}(\mathrm{W})$ & 200 & 428 & 65 & 13 & N.d. \\
\hline $10^{\mathrm{f}}$ & $\mathrm{Ru} / \mathrm{AC}(\mathrm{W})$ & 200 & 428 & 68 & 1 & 74 \\
\hline $11^{\mathrm{g}}$ & $\mathrm{Ru} / \mathrm{AC}(\mathrm{W})$ & 200 & 428 & 69 & N.d. & 79 \\
\hline 12 & $\mathrm{Ru} / \mathrm{AC}(\mathrm{W})$ & 200 & 428 & 75 & N.d. & 83 \\
\hline $13^{\mathrm{h}}$ & $\mathrm{Ru} / \mathrm{AC}(\mathrm{W})$ & 200 & 428 & 71 & N.d. & 83 \\
\hline 14 & $\mathrm{Ru} / \mathrm{AC}(\mathrm{N})$ & 200 & 428 & 71 & N.d. & 79 \\
\hline 15 & Ru/BP2000 & 200 & 428 & 61 & 1 & 81 \\
\hline 16 & $\mathrm{Ru} / \mathrm{XC72}$ & 200 & 428 & 68 & N.d. & 20 \\
\hline 17 & Ru/Ketjen Black & 200 & 428 & 67 & 1 & 82 \\
\hline 18 & $\mathrm{Ru} / \mathrm{AC}(\mathrm{W})$ & 20 & 428 & 71 & 9 & 6 \\
\hline
\end{tabular}

${ }^{a}$ Beet fiber (320 mg, containing 23\% hemicellulose), $\mathrm{H}_{2} \mathrm{O}$ (40 mL), $\mathrm{H}_{2}$ (5 MPa), 24 h. N.d.: Not detected.

${ }^{\mathrm{b}}$ Conversion of beet fiber is based on weight.

${ }^{\mathrm{c}}$ Based on hemicellulose weight.

${ }^{\mathrm{d}}$ Oligomers, ethylene glycol, and propylene glycol were obtained as by products.

${ }^{\mathrm{e}}$ In some cases, $\mathrm{C}_{6}$ sugars and sugar alcohols were also obtained in low yields.

${ }^{\mathrm{f}}$ Reaction time was $8 \mathrm{~h}$.

${ }^{\mathrm{g}}$ Reaction time was $16 \mathrm{~h}$.

${ }^{\mathrm{h}} \mathrm{All} \mathrm{Ru} / \mathrm{AC}$ catalysts were prepared from a $\mathrm{RuCl}_{3}$ precursor except entry 13, where it was prepared from a $\mathrm{Ru}(\mathrm{NO})\left(\mathrm{NO}_{3}\right)_{3}$ precursor. 
Table 2

Hydrogenolysis of arabinose by $\mathrm{Ru} / \mathrm{AC}(\mathrm{W})$ and recycle test ${ }^{\mathrm{a}}$.

\begin{tabular}{lllllll}
\hline Entry & $\begin{array}{l}\text { Type of } \\
\text { Catalyst }\end{array}$ & $\begin{array}{l}\text { Conv. } \\
{[\%]}\end{array}$ & $\begin{array}{l}\text { Yield }^{\mathrm{b}} \\
{[\%]}\end{array}$ & & & \\
\cline { 4 - 7 } & & Arabitol & Glycerol & EG $^{\mathrm{c}}$ & Total \\
\hline 19 & Fresh & 100 & 35 & 4 & 1 & 40 \\
20 & Reuse 1 & 100 & 34 & 5 & 1 & 40 \\
21 & Reuse 2 & 100 & 40 & 3 & 1 & 44 \\
22 & Reuse 3 & 100 & 42 & 3 & 1 & 46 \\
$23^{\mathrm{d}}$ & Reuse 4 & 71 & $83^{\mathrm{e}}$ & N.d. & 4 & 87 \\
\hline
\end{tabular}

${ }^{a}$ Arabinose (300 mg), Ru/AC(W) (200 mg), $\mathrm{H}_{2} \mathrm{O}$ (40 mL), $\mathrm{H}_{2}$ (5 MPa), $428 \mathrm{~K}, 24$ h. N.d.: Not detected.

${ }^{\mathrm{b}}$ The yield was calculated from HPLC analysis (based on weight).

${ }^{\mathrm{c}}$ Ethylene glycol.

${ }^{\mathrm{d}}$ Beet fiber (320 mg, containing 23\% hemicellulose) was used instead of arabinose.

${ }^{\mathrm{e}}$ Based on hemicellulose weight. 


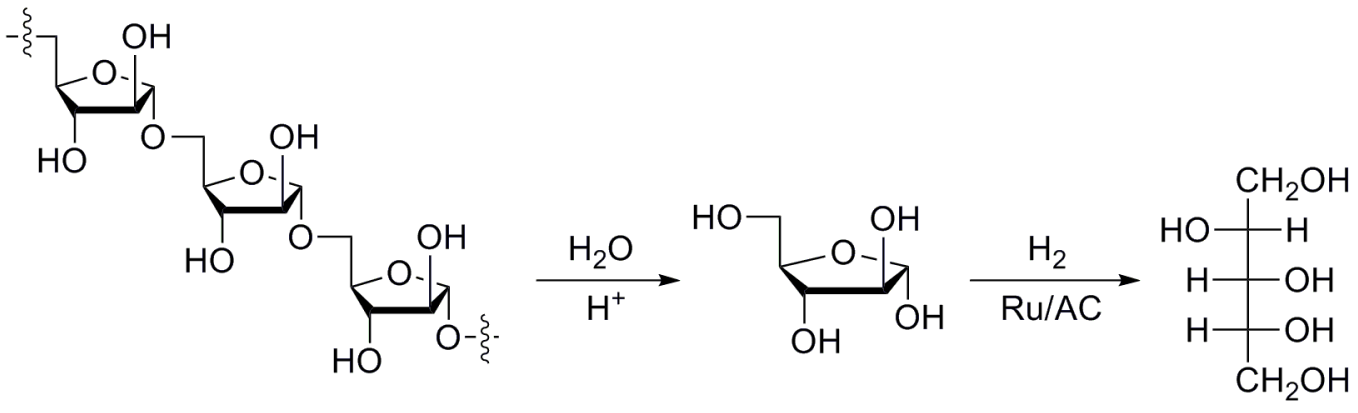

